\title{
Aconselhamento psicológico como área de fronteira
}

\author{
Maria Luisa Sandoval Schmidt* \\ Universidade de São Paulo, Instituto de Psicologia. São Paulo, SP, Brasil
}

Resumo: $O$ ensaio lança mão da noção de fronteira para analisar relações do campo do aconselhamento psicológico com a ordenação disciplinar da psicologia, partindo da experiência do Serviço de Aconselhamento Psicológico (SAP) do Instituto de Psicologia da Universidade de São Paulo (IPUSP). Articula referências teóricas do aconselhamento psicológico praticado com base na abordagem centrada na pessoa e do chamado pós-colonialismo na esfera da crítica literária, nomeadamente Edward Said e Homi Bhabha, assim como da antropologia, com Marc Augè e Vincent Crapanzano, e da história das ciências, com Bruno Latour, buscando refinar a visão da formação identitária do aconselhamento psicológico praticado pelo SAP. A análise parte de alguns elementos da fundação do SAP para, em seguida, dar atenção ao contexto e aos desdobramentos da metáfora e do conceito de fronteira na constituição identitária do campo de aconselhamento psicológico na relação com a ordem disciplinar no interior da psicologia e do IPUSP, tecendo, por fim, comentários sobre sua liminaridade e tomando como exemplo o plantão psicológico. Condição de liminaridade e posições minoritárias e/ou contra-hegemônicas no plano político e ideológico aparecem como qualidades do aconselhamento psicológico visto como região de fronteira.

Palavras-chave: aconselhamento psicológico, abordagem centrada na pessoa, fronteira, interdisciplinaridade.

O aconselhamento psicológico tem sido considerado área da psicologia, sustentando uma pluralidade de perspectivas teóricas e práticas que denunciam as perenes tensões entre a vocação organizadora e restritiva das divisões e os transbordamentos que afrontam suas ordens.

Esta característica, não exclusiva do aconselhamento psicológico, faz pensar que noções de campo, território ou terreno seriam mais fiéis à presença de ocorrências controversas, dinâmicas paradoxais e incoerências a desmentir a pretensa unidade e delimitação que a palavra "área" sugere. A provocação do móvel e mutante no interior das disciplinas e de suas subdivisões é o quê, aqui, conduz à apreciação da ideia de fronteira no campo, território ou terreno do aconselhamento psicológico.

$\mathrm{O}$ artigo faz um percurso pelo tema começando com a referência a alguns elementos da fundação do Serviço de Aconselhamentno Psicológico (SAP) do Instituto de Psicologia da Universidade de São Paulo (IPUSP), lugar de ancoragem do debate que se quer empreender; em seguida, dá atenção ao contexto em que a metáfora da fronteira começou a ser usada na e pela equipe do SAP; depois dessas duas menções introdutórias, passa à apresentação do conceito de fronteira na leitura da constituição identitária do campo de aconselhamento psicológico na relação com a ordem disciplinar no interior da psicologia, tecendo, por fim, comentários sobre a liminaridade do aconselhamento psicológico praticado pelo SAP, tomando como exemplo o plantão psicológico.

Autora correspondente: maluschmidt@terra.com.br

\section{Sobre o Serviço de Aconselhamento Psicológico do IPUSP}

O SAP do IPUSP tem mais de 40 anos, tendo sido criado em 1969. Em sua fundação, duas vertentes formativas destacam-se: o caráter de serviço de extensão em psicologia, na esfera do aconselhamento psicológico, que permitia sua localização num departamento ligado à psicologia educacional, e o apoio na perspectiva teórica da abordagem centrada na pessoa, representada principalmente por Carl Rogers ${ }^{1}$.

Desde sua criação, o SAP veio se constituindo num espaço, em nossos meios, para a prática do aconselhamento psicológico, para o ensino e a pesquisa baseados na abordagem centrada na pessoa e, mais recentemente, para o diálogo entre certa psicologia clínica social e o largo espectro de filosofias fenomenológica, fenomenológica existencial e existencialista.

A herança rogeriana, raiz de propostas clínico-pedagógicas do aconselhamento psicológico interessadas na legitimação de práticas profissionais nesse campo, foi transmitida por Rachel Lea Rosenberg, uma das iniciadoras do SAP e sua coordenadora até 1987, quando faleceu.

A construção do diálogo com a fenomenologia existencial e com o existencialismo, assim como a assunção explícita da necessidade de recorrer à sociologia, à antropologia e à história para empreender uma revisão crítica do campo de aconselhamento psicológico e das ideias de Carl

\footnotetext{
1 Ruth Sheeffer e Padre Benkö, no Rio de Janeiro e Oswaldo de Barros Santos, em São Paulo, foram, segundo Rosenberg (1987), os três principais introdutores da psicologia humanista no Brasil.
} 
Rogers foi tarefa assumida nos anos 1990, talvez em decorrência da perda da liderança intelectual e profissional de Rachel Rosenberg: a orfandade acadêmica, naquele caso, foi dolorosa e desafiante, sugerindo que para fazer jus ao legado do serviço e às suas ideias e práticas originais, fosse preciso reinventá-los, realizando, de novo, sua instalação.

A notícia é importante como indicação do contexto de interrogações e mudanças que marcou os anos 1990, no final dos quais a metáfora da fronteira passou a ser frequente para designar o aconselhamento psicológico por uma sugestão de Henriette Tognetti Penha Morato, integrante da equipe do SAP.

Em 1999, foi publicado o livro Aconselhamento psicológico centrado na pessoa: novos desafios. Organizado por Henriette Morato, o livro abrigou 24 capítulos, escritos por 30 autores - entre os quais a equipe do SAP -, colaboradores assíduos e alunos de graduação e pós-graduação que participaram do trabalho de nova instalação do serviço. De alguma forma, o livro condensa e expressa a década de interrogações e mudanças feitas na atmosfera de uma retomada crítica da abordagem centrada na pessoa, informada especialmente pelas leituras filosóficas e pela experimentação de práticas expandidas clínica e institucionalmente.

No capítulo "Aconselhamento psicológico e instituição: algumas considerações sobre o Serviço de Aconselhamento Psicológico do IPUSP", o termo região de fronteira aparece para esboçar e atualizar uma concepção de aconselhamento psicológico que subjaz à prática do SAP (Schmidt, 1999). A recuperação do texto torna possível situar sentidos e direções atribuídos à noção de região de fronteira naquele momento, das quais destacam-se dois.

O primeiro sentido, arraigado em uma interpretação consagrada sobre a formação da psicologia enquanto profissão, faz menção à sua constituição composta de elementos da medicina e da educação $0^{2}$ : esta composição que no campo mais amplo da psicologia indicaria vertentes ou mesmo áreas específicas (a psicologia educacional afiliada à educação; a psicologia clínica afiliada ao modelo médico), aparece, no aconselhamento psicológico e, especialmente, no caso da entrada de Rogers nesse campo, como lugar ou região de fronteira. Ou seja, o aconselhamento psicológico teria se instalado entre as práticas convencionalmente identificadas como clínico-psicológicas e educacionais.

Trata-se da figuração conjuntiva do par educação e medicina, e não da disjuntiva, mais comum na formação identitária das áreas da psicologia, educação ou medicina. Por exemplo, os grupos de encontro propostos por Rogers eram, ao mesmo tempo, dispositivos de aprendizagem (educacionais) e de mudança e autoconhecimento (terapêuticos). Essa condição ou qualidade miscigenada está presente no plantão psicológico, na supervisão de apoio psicológico e nas oficinas com recursos expressivos, práticas centrais naquele período do SAP. Cabe, também, pontuar

2 Sobre essa interpretação da composição da psicologia pela educação e medicina, ver Antunes (2003). que essas práticas - o plantão, desde o início, a supervisão de apoio psicológico e as oficinas com recursos expressivos, a partir dos anos 1990 - foram próprias do SAP, dentro do espírito de experimentação que o marca ${ }^{3}$.

Outro sentido, acenando para a interdisciplinaridade, diz respeito ao esforço de responder às demandas por ajuda psicológica desde uma compreensão psicossociocultural, esforço em que concorrem recursos teórico-práticos de outras disciplinas sociais, bem como os saberes populares e do senso comum, trazidos principalmente pela clientela.

A percepção das duas qualidades fronteiriças do aconselhamento psicológico - encontro e fusão de "modelos" inspiradores da psicologia numa região mista e problemática para a ordem disciplinar interna à psicologia; abertura para o diálogo interdisciplinar e com os saberes populares e do senso comum - foi, de certo modo, convite para trilhar uma senda de radicalização teórica e prática capaz de reconhecer uma herança, e, no mesmo movimento, reconhecer sua transformação e impermanência no processo de seu deslocamento no tempo, sofrendo a influência do debate sobre as dimensões epistemológica e social da(s) psicologia(s) e no processo de seu deslocamento territorial, instalando-se em uma universidade pública brasileira, a Universidade de São Paulo (USP).

Dito de outra maneira, a metáfora da fronteira fez ver a face ativa da apropriação da tradição do aconselhamento psicológico nascido nos Estados Unidos, ensaiando timidamente uma legitimação de modos de fazer e pensar híbridos, caboclos, do hemisfério sul.

Com alguma frequência, no embate das teorias psicoterapêuticas no interior do IPUSP, o aconselhamento psicológico foi tomado por eclético e frágil conceitualmente: a fronteira estendeu-se, assim, como lugar de tradução deste eclético e frágil na valorização das misturas de modelos e do diálogo entre disciplinas.

\section{Aconselhamento psicológico e fronteira}

Segue-se, então, tratando do alargamento desse entendimento do aconselhamento psicológico como área de fronteira, que, para ler ou interpretar a situação particular do SAP, muito se aproveitou do contato com os escritos de autores do chamado pós-colonialismo na esfera da crítica literária, sobretudo Edward Said e Homi Bhabha, assim como da antropologia, com Marc Augè e Vincent Crapanzano, e da história das ciências, com Bruno Latour. Nesses autores, não com exclusividade, mas com maior ênfase, foi possível encontrar sustentação conceitual para refinar a visão da formação identitária do aconselhamento psicológico que o serviço vinha praticando, considerando, de partida, a noção de fronteira.

Passa-se, portanto, a apresentar e discutir a noção de fronteira, buscando pensar o campo de aconselhamento psicológico na relação com a ordem disciplinar e

3 Sobre essas práticas, ver Morato (1999). 
a liminaridade de suas práticas aqui inventadas, especialmente o plantão psicológico.

Na introdução do livro O local da cultura, Homi Bhabha $^{4}$ (1998) chama atenção para a experiência contemporânea de viver nas fronteiras do presente, expressa, para o autor, no uso do prefixo "pós" para designar nosso tempo (pós-modernismo, pós-colonialismo, pós-feminismo, entre outros): referência a um além "que não é nem um novo horizonte, nem um abandono do passado", mas que assinala um momento de trânsito "em que espaço e tempo se cruzam para produzir figuras complexas de diferença e identidade, passado e presente, interior e exterior, inclusão e exclusão" (p. 19).

Assim como Marc Augè (1997), Bhabha indica o indivíduo como lugar da articulação de pertencimentos múltiplos e vetor de trânsitos que se singularizam e se desprendem de orientações pautadas por instituições ou grupos.

Essa percepção do lugar do indivíduo, ou, na contrapartida, do enfraquecimento da centralidade das grandes instituições na formação identitária de indivíduos e coletivos, tem como decorrência teórica e política o interesse de "passar além das narrativas de subjetividades originárias e iniciais e de focalizar aqueles momentos ou processos que são produzidos na articulação de diferenças culturais" (Bhabha, 1998, p. 20).

Trata-se de focalizar, na linguagem de Bhabha (1998), entre-lugares que "fornecem o terreno para elaboração de estratégias de subjetivação - singular e coletiva - que dão início a novos signos de identidade e postos inovadores de colaboração e contestação" (p. 20).

Até aqui, destacam-se, então, dois elementos preciosos para a discussão sobre formação identitária de indivíduos ou coletivos ${ }^{5}$ : a autoconsciência de nosso contemporâneo como momento de trânsito entre passado e futuro (entre tradição e horizonte); a focalização de processos e momentos de articulação de diferenças mais do que de narrativas de origem e fundação.

Como pensar o aconselhamento psicológico pelo viés de momentos ou processos de articulação de diferenças (culturais)? É possível transpor essa sugestão metodológica para a análise das relações institucionais - políticas, ideológicas, epistemológicas - de um âmbito da psicologia com o seu campo mais amplo?

Sabe-se que Rogers, na primeira metade do século $\mathrm{XX}$, produziu mudanças na esfera fortemente disciplinar de ordenamento dos saberes e práticas psicológicos em áreas e subáreas bem recortadas e definidas. Afrontou as divisões entre orientação, aconselhamento e psicoterapia, bem como entre clínica e educação; desafiou o poder do

4 Intelectual indiano, radicado atualmente nos Estados Unidos, professor de literatura e inglês em várias universidades norte-americanas, entre as quais Anne F. Rothenberg e Havard.

5 A adequação da transposição desses elementos para análise da formação identitária de um serviço (SAP) e de uma área da psicologia (aconselhamento psicológico) não é evidente. Porém, pode ajudar a pensar a área como uma instituição e o serviço, pela sua compleição em equipe, como um coletivo. especialista e as reservas de mercado para atividade exclusiva de psicólogos (leigos e outros profissionais poderiam igualmente cuidar e educar) ${ }^{6}$.

Essa diferença foi, principalmente, política? Criou uma subcultura no interior da psicologia? Como a importação das ideias e práticas rogerianas, nos anos 1960, e da Abordagem Centrada na Pessoa, posteriormente, incide sobre a(s) psicologia(s) brasileira(s), paulistana(s) e uspiana(s)? São questões que a aproximação do aconselhamento psicológico como região de fronteira suscita.

Em nosso meio, houve uma tendência, até hoje ativa, de reduzir o aconselhamento psicológico formado no SAP a uma psicoterapia de tipo rogeriana; o que não deixa de ser uma maneira de neutralizar suas virtudes rebeldes no domínio das psicoterapias convencionais.

A separação entre psicoterapia e aconselhamento, por sua vez, reflete o empenho da ciência psicológica em realizar competente peritagem da clientela, distribuindo-a entre formas de assistência conforme suas reais necessidades. A lógica disciplinar insinua que a solidez dos dispositivos psicodiagnósticos, que devem ser adquiridos pelos profissionais em sua formação, prescreve a assistência adequada a cada caso. A lógica disciplinar organiza o terreno da assistência e do tratamento e distribui a clientela, pelo diagnóstico, no interior dessa organização a qual produz, no plano imaginário, estereótipos e generalizações que servem àquilo que Bruno Latour (1994), no livro Jamais fomos modernos, chama de purificação do conhecimento científico, com a qual a ordem disciplinar busca expurgar de seu campo as redes em que seus conhecimentos se envolvem com sujeitos e coletivos e a existência de objetos híbridos que, justamente, "não podem ou merecem ser conhecidos".

Exemplo dessas simplificações purificadoras: a psicoterapia está ligada ao par saúde/doença, visa o tratamento de patologias ou graves transtornos emocionais, requer tempos prolongados; o aconselhamento psicológico está ligado ao eixo adaptação/inadaptação, visa à escolha e às crises situacionais, sua clientela não tem "comprometimentos na estrutura de personalidade", podendo ocorrer em tempos abreviados (Scheeffer, 1976).

Este mesmo imaginário, combinando, no IPUSP, as qualidades do aconselhamento psicológico - adaptativo, para clientela sem transtornos graves, referido a processos de escolha e crises, realizado em tempos breves - com sua redução à psicoterapia de tipo rogeriano, vai colocá-la em oposição à psicoterapia profunda, de base psicanalítica. Profundidade e superficialidade são matizes do mapa das tendências hegemônicas e não hegemônicas no território das teorias e práticas psicológicas.

Esse mapa vem fazendo uso, historicamente, da ideia de três forças: a primeira é a do behaviorismo; a segunda, a psicanálise; a terceira, o humanismo, abrangendo teorias psicológicas que sofreram influência da fenomenologia, da fenomenologia existencial e do existencialismo.

6 Sobre esta interpretação da posição de Rogers na ordenação disciplinar da psicologia ver Schmidt (2009). 
Esta maneira de enxergar o campo pode parecer, talvez, superada, mas lembra-la serve para apontar algumas imagens redutoras, persistentes e poderosas, a partir das quais se retoma a noção de identidade de fronteira para pensar as tendências hegemônicas e não hegemônicas.

Ao behavirismo ou, mais recentemente, à abordagem cognitivo-comportamental, atribui-se a eficácia, e sua presença é forte na esfera médico-psiquiátrica. A psicanálise caracteriza-se pela profundidade e rigor conceitual-prático, sendo marcante na formação clínica no IPUSP e alhures; a terceira força, uma espécie de saco de gatos onde caberia todo o resto, é alternativa às duas outras forças que já se anunciam, então, hegemônicas. $\mathrm{O}$ adjetivo "alternativo" sugere, nas relações de forças, posição não hegemônica e identidade intersticial da chamada terceira força.

Se for permitido imaginar os grupos de ensino e pesquisa afiliados a correntes teórico-práticas diferentes como comunidades que compartilham interesses e valores; se recai o olhar sobre tais grupos enquanto formas segmentadas e fragmentadas no interior da universidade, não necessariamente unidas pela identificação com um projeto comum, então a seguinte observação de Bhabha (1998) sobre a existência de conflitos e concorrência no interior de comunidades pós-coloniais ou entre elas pode ser útil. $\mathrm{O}$ autor refere-se à

formulação de estratégias de representação ou aquisição de poder no interior das pretensões concorrentes de comunidades em que, apesar de histórias comuns de privação e discriminação, o intercâmbio de valores, significados e prioridades pode nem sempre ser colaborativo e dialógico, podendo ser profundamente antagônico, conflituoso e incomensurável. (p. 20)

No que diz respeito à configuração disciplinar das áreas e correntes psicológicas no contexto universitário, é possível identificar antagonismos, conflitos e disputas de poder, a despeito de alguma história de comunalidade em torno de pautas corporativas. $\mathrm{O}$ vigor da questão é corroborado pelas crises desencadeadas por diferenças, denunciando as dificuldades de diálogo e colaboração - como no exemplo das tentativas de criar um centro-escola integrado no IPUSP. A geografia dos lugares e poderes institucionais é pautada pela formação de pensamentos e práticas hegemônicas e de minorias.

Hegemonia, como mostra Said (1990), acompanhando Gramsci (2001), trata-se, nas sociedades não totalitárias, da predominância de certas formas culturais e da maior influência exercida por certas ideias: uma espécie de liderança cultural. Nesse ponto, é possível arriscar interpretar a posição do SAP e do aconselhamento psicológico como minoritária: posição não hegemônica e, às vezes, exercendo resistência contra-hegemônica à ordem disciplinar e aos processos de institucionalização, aquisição e acumulação de poder.

A identidade de fronteira procura, aqui, conferir autoridade às formas híbridas e moventes das ideias e práticas, negociando sua possibilidade de se expressar "a partir da periferia do poder".
De acordo com Bhabha (1998), a expressão da minoria depende menos da persistência da tradição e mais do poder da tradição de se inscrever pelas contingências e contradições que persistem na vida das minorias.

Para entender o aconselhamento psicológico e o SAP nessa direção, é preciso pensar se a noção de minoria ou marginalidade relativa se sustenta em condições e contradições que, ao atualizar a tradição de liminaridade, dão corpo a um lugar intersticial, colocando-se sempre e novamente em tensão com os processos de forte institucionalização e acumulação de poder. Ainda, não se trata da herança de uma identidade pronta e oferecida pela tradição, mas, talvez, da invenção de uma tradição que faça jus à condição de liminaridade, como tentativa de entender, pelo recurso à tradição, de que forma o serviço chegou até este presente e este lugar, atravessado pela contradição expressa na busca identitária do psicólogo e a dissolução de sua afirmação como especialista.

A tensão com os processos de institucionalização pesada e com a acumulação de poder passa, necessariamente, pela crítica ao especialista, trazendo a dimensão política para dentro da atividade profissional de ensino, atendimento e pesquisa. O argumento especialista, segundo Said (1990), bloqueia a percepção da dimensão política de toda atividade acadêmica e intelectual, presente em todas as áreas.

Nesse sentido, as atitudes e ideias contra-hegemônicas da área e do serviço manifestam-se também (e sobretudo) como política da psicoterapia, da clínica social, da formação de profissionais de saúde e educação, interessada no compartilhamento do poder e nas composições autogestionárias em coletivos de alunos e trabalhadores e na autodeterminação e autonomia dos atores, incluindo a clientela atendida individualmente.

$\mathrm{Na}$ fronteira, o aparecer é fazer-se presente, apresentar-se e presentificar-se e, talvez, a visão de aconselhamento psicológico que vem sendo construída no SAP tenha desejado, aspirado e projetado em um horizonte ideal ser condição ou lugar de apresentação e presentificação da minoria, do contra-hegemônico, do dissidente e do diferente.

Bhabha (1998) traz como epígrafe da introdução de seu livro uma frase de Heidegger (1951) que diz: "Uma fronteira não é o ponto onde algo termina, mas, como os gregos reconheceram, a fronteira é o ponto a partir do qual algo começa a se fazer presente"

\section{Plantão psicológico: um exemplo de liminaridade}

Dessa concepção de fronteira deriva-se um último conjunto de comentários sobre o caráter liminar das

\footnotetext{
7 A citação é retirada da tradução de um texto de Heidegger (1951) chamado Construir, habitar, pensar, no qual, quando foi exposto pela primeira vez, o autor reflete sobre a construção de habitações de massa que procuravam responder às necessidades de moradia após a destruição das cidades alemãs na Segunda Guerra Mundial. Para ele, as construções impediam a própria possibilidade de habitar. Ver Heidegger (1951).
} 
práticas do aconselhamento psicológico, tomando o exemplo do plantão psicológico.

Crapanzano (2005), no texto Horizontes imaginativos e o aquém e o além, aponta que a cultura euro-americana tende a enfatizar os elementos que compõem uma relação mais do que a própria relação. Segundo o autor,

concentramo-nos em categorias e sistemas classificatórios baseados nessas categorias, em vez de em sistemas determinados pela relação e pela sintaxe. Acentuamos a coesão e moderamos a eclipse, a interrupção e a pausa. De modo geral, não lemos em função do silêncio e do não dito. (p. 372)

A atenção para a relação entre elementos pode, por sua vez, enfatizar "o intervalo, a lacuna, o silêncio, o entre e o em meio a." (Crapanzano, 2005, p. 372).

Tal apreensão intersticial traduz-se na busca por relações ou práticas nas quais a experiência de indivíduos ou grupos possa se apresentar fora ou a certa distância das leituras classificatórias ou "classificantes". De outra perspectiva, busca relações e práticas capazes de estimular e sustentar o silêncio fecundo, os paradoxos do querer e não querer, as realidades intermediárias da ambiguidade (nem isso, nem aquilo; tanto isso, quanto aquilo) e da ambivalência (ora isso, ora aquilo), os estados de travessia e de passagem, as possibilidades imaginativas, a invenção.

As qualidades do liminar não são, contudo, ilimitadas, entrando em contato com o cotidiano e a tradição das práticas de atendimento psicológico; cotidiano e tradição afrontados pela "atitude antiestrutural da liminaridade que, sendo o reino da pura possibilidade, é, também, a fonte de novas ideias e relações de "cuidado".

O plantão psicológico, até onde se sabe, foi criado pelos primeiros adeptos da terapia centrada no cliente em São Paulo, entre eles Rachel Lea Rosenberg. Seu propósito principal era oferecer uma escuta psicoterapêutica no momento mesmo em que alguém fizesse o movimento por sua busca e uma acolhida dispensando os pré-requisitos psicodiagnósticos e burocrático-administrativos comuns em consultórios e clínicas de psicologia. Foi o que se chamaria hoje de um serviço portas abertas, não fosse a circunstância de, algumas vezes, o atendimento realizar-se nos bancos do pátio do prédio da Maria Antônia, por exemplo.

Aos poucos, com a criação do SAP, o plantão foi se tornando uma prática estruturada em torno da disposição de estagiários de psicologia e profissionais (psicólogos e outros $^{8}$ para o atendimento de todas aqueles que chegassem em períodos determinados e amplamente divulgados, fixando-se às quartas-feiras, desde então.

O Plantão, como porta de entrada do SAP, constitui uma abertura para a diversidade, pluralidade e singularidade da clientela que chega e uma exposição do

8 Nos anos 1970, o SAP teve equipes multidisciplinares com assistente social e psiquiatra. Depois, paulatinamente, a equipe tornou-se exclusivamente composta por psicólogas. Nos anos 1990 teve, por um período, um psiquiatra. serviço às suas demandas; em contrapartida, a exposição do serviço está relacionada com a necessidade de criar modos de responder apurados na escuta e no diálogo com a clientela.

Ocasião de escuta e diálogo, as entrevistas de plantão podem ser compreendidas como espaço e tempo de mediação e trânsito de identidades e diferenças; inclusões e exclusões; passado e presente; interior e exterior, na medida em que procuram transpor a proteção facultada por dispositivos de diagnóstico e triagem, expondo-se à plasticidade dos encontros e às dimensões próprias e significati$\operatorname{vas}^{9}$ da experiência humana.

As identidades profissionais de psicólogos e estagiários de psicologia encontram-se com um sem-número de expectativas e imagens da clientela sobre psicólogos, implicando em que ambos podem desalojar-se de regiões familiares de reconhecimento ou estranhamento de diferenças pessoais, sociais e culturais. Diferenças de posição social, inserção em subculturas e lugares institucionais constituem-se, no encontro, como possibilidades e/ou limites para o diálogo e o cuidado. Identidades e diferenças são matéria da manufatura sutil em que uns e outros buscam afirmar-se, diferindo e distinguir-se, se afirmando. Trata-se do intento de reconhecer assimetrias e diferenças, sem hierarquizá-las: intento difícil, uma vez que, justamente, a hierarquia pela diferença é potente organizador da vida social e institucional numa sociedade e numa universidade regidas pela competição e pela lógica de domínio do outro.

A mutualidade dos testemunhos - $\mathrm{o}$ estagiário $\mathrm{e}$ o profissional legitimados, pelo cliente, no lugar de cuidadores e o cliente sendo, assim, acolhido em seu sofrimento - e a possibilidade de comutação de lugares - que o cliente acolha o estagiário ou profissional em seu desejo de ser psicólogo e este reconheça o cliente como portador de uma experiência digna e interessante - permitirão, talvez, desarmar convenções clínicas, deslocar lugares de poder e saber, rever atitudes e valores preconceituosos, criticar aproximações moralizantes, normativas e "psicopatologizantes".

A política do plantão é aquela de buscar o cuidado como resultado das negociações possíveis entre saber acadêmico e senso comum e saber popular, dos quais são porta-vozes tanto aqueles que atendem quando aqueles que são atendidos.

A construção do cuidado dá-se num espaço de intimidade e privacidade que abre feições da cidade e jeitos de habitá-la: cada cliente é mensageiro que, ao apresentar-se

9 "O significativo associa a verdade que nós podemos perceber nele às qualidades do sentimento que tem a nossa confiança para dele extrair o completamente novo, que é ao mesmo tempo compreensão e decisão, uma obstinação retemperada, qualquer coisa que dispõe de um conteúdo ao mesmo tempo mental e psíquico e que 'exige' de nós ou dos outros um certo tipo de comportamento; poder-se-ia dizer, e no que diz respeito à estupidez isso é essencial, que o significativo é acessível tanto ao aspecto racional como ao aspecto afectivo da crítica. O significativo é, também, ao mesmo tempo, o contrário da estupidez e da brutalidade; e o mal-entendido geral que permite hoje aos afectos asfixiar a razão, em vez de lhe dar asas, fica abolido na noção de significativo" (Musil, 1994, p. 35). 
a si mesmo, apresenta a trama social em que sua existência faz sentido. Para compreender quem chega é, por isso, conveniente perguntar quem ele é e de onde ele vem ou onde ele está. Situar-se é tarefa das relações de cuidado que podem ser concebidas no trânsito entre os mundos interno e externo, tão caros às teorias psicológicas: o que se busca (e o que se encontra, eventualmente) não está nem dentro, nem fora dos indivíduos, mas entre eles, no mundo comum. Reconhecer e estranhar o próprio e o alheio, aproximar e afastar coisas e pessoas, valores e sentimentos são trabalho de situar-se.

As entrevistas de plantão vistas como lugar de passagem, travessia, espaço de suspensão do cotidiano e do habitual, podem concorrer para o cuidado num sentido mais fortemente existencial ou coexistencial.

Resta dizer que esta interpretação afetivo-conceitual do aconselhamento psicológico e do plantão psicológico praticados pelo SAP tem, de um lado, a pretensão de roçar camadas de suas realizações e, de outro, a certeza de que a noção de fronteira os fecunda com horizontes imaginativos, utópicos, com os quais se quer enfrentar esses nossos tempos de objetivação, limitação e cristalização dos modos de viver, lutar e sofrer e de redução do cuidado à administração de remédios em que as formas de viver, lutar e sofrer ficam reduzidas às figuras da patologia.

\section{Counselling psychology as a frontier area}

Abstract: The article uses the notion of frontier to analyze the relations between the field of Counselling Psychology and the disciplinary order of psychology, based on the experience of the Serviço de Aconselhamento Psicológico (SAP) [Counselling Psychology Service] of the Psychological Institute of the University of São Paulo (IPUSP), Brazil. It articulates the theoretical references of the practiced psychological counselling based on the person centered approach and on what is called the post-colonialism in the sphere of literary criticism, namely Edward Said and Homi Bhabha, as well as from anthropology, with Marc Augé and Vincent Crapanzano, and from the history of science, with Bruno Latour, seeking to refine the vision of the identity formation of psychological counselling practiced by SAP. The analysis initiates by presenting some elements of SAP, and then focus on the context and consequences of metaphor and the concept of frontier in the identity constitution of counselling psychology in relation to the disciplinary order within the psychology and the IPUSP, turning finally to comments on their liminality, taking the psychological emergency attendance services as an example. Condition of liminality and minority and/or counter-hegemonic political and ideological positions appear as qualities of psychological counselling viewed as a frontier area.

Keywords: counseling psychology, person-centered approach, frontier, interdisciplinarity.

\section{Soutien psychologique comme zone de frontière}

Résumé: Cet essai explore la notion de frontière pour analyser des relations du domaine du Soutien Psychologique avec l'ordonnance des disciplines de la Psychologie, à partir de l'expérience du Serviço de Aconselhamento Psicológico (SAP) [Service de Soutien Psychologique] de I'Institut de Psychologie de I'Universidade de São Paulo (IPUSP), au Brésil. L'étude articule des références théoriques du Soutien Psychologique pratiquée sur la base de l'Approche Centrée sur la Personne et du post-colonialisme dans la sphère de la critique littéraire, en particulier Edward Said et Homi Bhabha, ainsi que de l'anthropologie, chez Marc Augè et Vincent Crapanzano, et de I'histoire des sciences, chez Bruno Latour, cherchant à affiner la vision de la formation identitaire du soutien psychologique pratiquée par le SAP. II part de certains éléments de la fondation du SAP et puis il concentre l'attention sur le contexte et les développements de la métaphore et du concept de frontière dans la constitution identitaire du domaine de soutien psychologique par rapport à l'ordonnance des disciplines au sein de la psychologie et de I'IPUSP. Finalement, il formule des commentaires sur la liminalité, en prenant comme exemple le psychologue de garde. L'état de liminalité et des positions minoritaires et/ou contre-hégémoniques dans le cadre politique et idéologique apparaissent comme des qualités du soutien psychologique vu comme zone de frontière.

Mots-clés: soutien psychologique, approche centree sur la personne, frontiere, interdisciplinarite.

\section{Consejería psicológica como zona de frontera}

Resumen: El ensayo hace uso de la noción de frontera para analizar las relaciones del campo de Consejería Psicológica con el orden disciplinario de la Psicología, apoyado en la experiencia del Serviço de Aconselhamento Psicológico (SAP) [Servicio de Consejería Psicológica] del Instituto de Psicología de la Universidad de São Paulo (IPUSP), Brasil. Articula referencias teóricas de Consejería Psicológica practicadas con base en el abordaje centrado en la persona y del llamado postcolonialismo en el 
ámbito de la crítica literaria, en particular Edward Said y Homi Bhabha, así como de la antropología, con Marc Augè y Vincent Crapanzano, y de la historia de las ciencias, con Bruno Latour, buscando mejorar la visión de la formación identitaria de la Consejería Psicológica practicada por el SAP. El análisis parte de algunos elementos de la fundación del SAP para, después, poner atención al contexto y a las consecuencias de la metáfora y del concepto de frontera en la constitución identitaria del campo de consejería psicológica en relación con el orden disciplinario en el interior de la psicología y del IPUSP, tejiendo, por fin, comentarios sobre su liminalidad y tomando como ejemplo la guardia psicológica. La condición de liminalidad y posiciones minoritarias y/o contra hegemónicas en el plano político e ideológico aparecen como cualidades de la consejería psicológica vista como una región fronteriza.

Palabras clave: consejería psicológica, abordaje centrado en la persona, frontera, interdisciplinaridad.

\section{Referências}

Antunes, M. A. M. (2003). A psicologia no Brasil: leitura sobre sua constituição. São Paulo, SP: EDUC.

Augé, M. (1997). Por uma antropologia dos mundos contemporâneos. Rio de Janeiro, RJ: Bertrand Brasil.

Bhabha, H. K. (1998). O local da cultura. Belo Horizonte, MG: Ed. UFMG.

Crapanzano, V. (2005). Horizontes imaginativos e o aquém e além. Revista Antropologia, 48(1), 363-384. Recuperado de http:// www.scielo.br/scielo.php?script=sci_arttext\&pid=S0034$77012005000100009 \& \operatorname{lng}=\mathrm{en} \& \mathrm{nrm}=\mathrm{iso}$

Gramsci, A. (2001). Cadernos do cárcere (Vol. 2). Rio de Janeiro, RJ: Civilização Brasileira.

Heidegger, M. (1951). Construir, habitar, pensar. Recuperado de http://www.prourb.fau.ufrj.br/jkos/p2/ heidegger_construir,\%20habitar,\%20pensar.pdf

Latour, B. (1994). Jamais fomos modernos. Rio de Janeiro, RJ: Ed. 34.

Morato, H. T. P. (1999). (Org.). Aconselhamento psicológico centrado na pessoa: novos desafios. São Paulo, SP: Casa do Psicólogo.

Musil, R. (1994). Da estupidez. Lisboa: Relógio D’Água.
Rosenberg, R. L. (1987). Biografia de um serviço. In R. L. Rosenberg (Org.), Aconselhamento psicológico centrado na pessoa. São Paulo, SP: EPU.

Said, E. W. (1990). Orientalismo: o Oriente como invenção do Ocidente. São Paulo, SP: Companhia das Letras.

Scheeffer, R. (1976). Teorias de aconselhamento. São Paulo, SP: Atlas.

Schmidt, M. L. S. (1999). Aconselhamento psicológico e instituição: algumas considerações sobre o Serviço de Aconselhamento Psicológico do IPUSP. In H. T. P. Morato (Org.), Aconselhamento psicológico centrado na pessoa: novos desafios. São Paulo, SP: Casa do Psicólogo.

Schmidt, M. L. S. (2009). O nome, a taxonomia e o campo do aconselhamento psicológico. In H. T. P. Morato, C. L. B. T. Barreto \& A. P. Nunes, (Orgs.), Aconselhamento psicológico numa perspectiva fenomenológica existencial (pp. 1-21). Rio de Janeiro, RJ: Guanabara Koogan.

Recebido: $15 / 04 / 2014$ Aceito: 03/10/2014 